\title{
Defects of large diameter drilled piles
}

\author{
Jaroslav Žák ${ }^{1, *}$ and Jiř Žák ${ }^{2}$ \\ ${ }^{1}$ Department of Civil Engineering, Institute of Technology and Business in České Budějovice, \\ Okružní 517/10,370 01 České Budějovice, Czech Republic \\ ${ }^{2}$ Faculty of Science, Masaryk University in Brno, Kotlářská 267/2, 61137 Brno, Czech Republic
}

\begin{abstract}
High-rise buildings are often based on large-diameter bored piles. Their flaws and faults then affect the behavior of the entire building and can significantly influence the statics. Correct processes is therefore necessary to pay attention. The article describes the most common wrong ways of implementing the recommendations and how to prevent them. The design of piles is based on calculated loads, respectively forces and moments acting on the piles and of parameters of the environment. There may, of course, committed a number of mistakes, but we further assume piles to be designed in accordance with all applicable standards. We will focus mainly on technological progress of the implementation of drilling and concreting piles and show the most common mistakes. Bored piles can be performed using a casing or without them. In most cases, the use of casings is possible. Recommendations how to ensure the quality and to protect the environment are also given.
\end{abstract}

\section{Introduction}

A designer must take into a consideration calculated strain that is what forces and moments are acting upon piles and also parameters of the surroundings (subgrade) when designing a pile. One may make several mistakes here however let's assume properly designed pile which meets all the required standards. We will not discuss the actual propagation of the calculated bending moment from the base of the pile a whether moments calculated along the length of the pile are correct. Let's also assume that the longitudinal and spiral reinforcement was correctly designed.

Further we will discuss mostly technological procedure of drilling and concreting piles and we will point out the most common mistakes. Bored piles can be performed using a casing or without them. In most cases, the use of casings is possible. The author recommends their usage due to ensuring of higher quality of concrete and also as environment protection.

\section{Theoretical formulas}

There are 3 main equations which can be used to describe and simulate flow of concrete paste, see [1-5] for more details. The main equations which is being used is the equation of

* Corresponding author: jzax@seznam.cz 
motion. Others are the continuity equation and the energy equation. According to the type of approximation and whether we consider concrete paste to be a Newtonian fluid or nonNewtonian fluid, Navier-Stokes equation or the Cauchy equation of motion can be used. Cauchy equation of motion is listed below (1), (2)

$$
\rho\left(\frac{\partial v}{\partial t}+v \cdot \nabla v\right)=\nabla \cdot \sigma+\rho g
$$

The term $\mathbf{v}$ is the 4 dimensional (time being one dimension) and 3 directional velocity, $\rho$ is the density, $t$ is the time, $\mathbf{g}$ is the gravity and $\boldsymbol{\sigma}$ is the (total) stress tensor. The stress tensor is given by

$$
\sigma=-\rho I+T
$$

In general and as shown above, the stress tensor is decomposed into an isotropic pressure term $\rho$ and an extra stress contribution $\mathbf{T}$, commonly known as the extra stress tensor. $\mathbf{I}$ is the unit dyadic.

Second equation is the continuity equation (3) which is often used to calculate pressure correction while solving Eq. (1). It writes

$$
\frac{\partial v}{\partial t}=-(\nabla \cdot \rho v)
$$

For liquids, which are much denser than gasses, the incompressibility constraint is often assumed, and the above equation can be written as

$$
(\nabla \cdot v)=0
$$

The last of the governing equations is the energy equation, which is used to determine possible temperature variations. However, during flow of cement based materials, isothermal conditions are often assumed and the energy equation is often omitted.

\section{Technological procedure}

Mistakes can be found even in the technological regulations; however most common mistakes are seen because the regulation were not properly met. Distance wheels from various materials are being used when constructing piles. Wheels not properly attached to the main reinforcement. Designed diameter of piles and reinforcement does not allow smooth insertion into the drilled hole. Concreting is being carried out in a wrong way, finishing of the concreting is being carried out in the wrong way. Samples of the concrete are being taken from improper places (not risky locations) and are not being taken from the risky places.

\subsection{Cover of a reinforcement}

To ensure cover of reinforcement distance wheels can be used (see Fig. 1). Plastic distance wheels turned out to be unsuitable because of their deformation while placing. Insufficient attention is often paid to manufacturing wheels, they are treated as not important and 
auxiliary part of the construction. Their incorrect manufacture can however cause serious issues. Distance wheels are sometimes manufactured with inner diameter too big and its centre is not located within centre of the wheel. Afterwards distance wheel can crush, break or damage itself and can cause problems for smooth insertion of pile reinforcement.

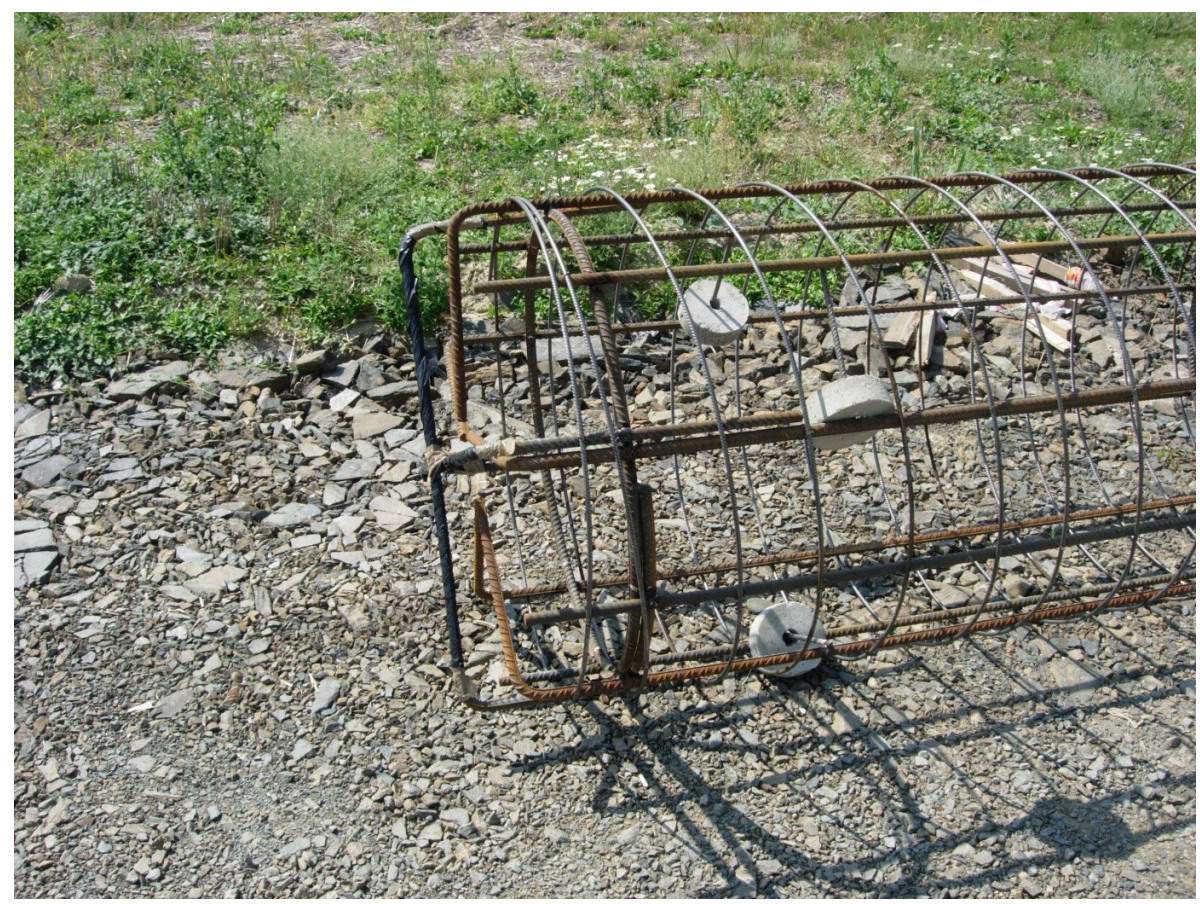

Fig. 1. Distance wheel of a pile reinforcement.

Distance wheels with too big or unsymmetrical opening must be removed from the construction.

It is often the case that the distance wheels are not placed correctly on the pile reinforcement. Designers often design diameter of the wheel as a standard cover. Because of this the wheel must be placed on the outer edge of the spiral. Also a designer can design diameter of the drill expanded only by casing insertion of pile reinforcement is practically infeasible. Reaction of a contractor is often placing the distance wheels on the inner edge of the spiral (see Fig. 2) however by doing this the actual cover is reduced. You can clearly see that reinforcement is in the contact with the casing (see Fig. 2). Casing will not be working properly or even it can happen that after removal of the casing the reinforcement can be moved from the concrete. Early onset of corrosion is inevitable.

Pile reinforcement seems to be rigid but it has tendency to undulate along its length. Pile reinforcement should be designed to be sufficiently rigid due to better manipulation when inserting. Designers often design only three wheels in the cut and reinforcement of smaller profiles in order to cut costs. Mathematically it is sufficient to ensure proper cover but not realistically. Undulation of pile reinforcement, deformation and movement of wheels can cause that the pile reinforcement may be in touch with the casing. Wheels must be therefore placed in single cut and turned by 60 degrees to each other. Wheels must be placed on the outer side and the diameter of the drill must be designed with sufficient reserve allowing good manipulation with pile reinforcement in drill hole. Each layers of the wheel must not be too far away and must be turned by 60 degrees. 


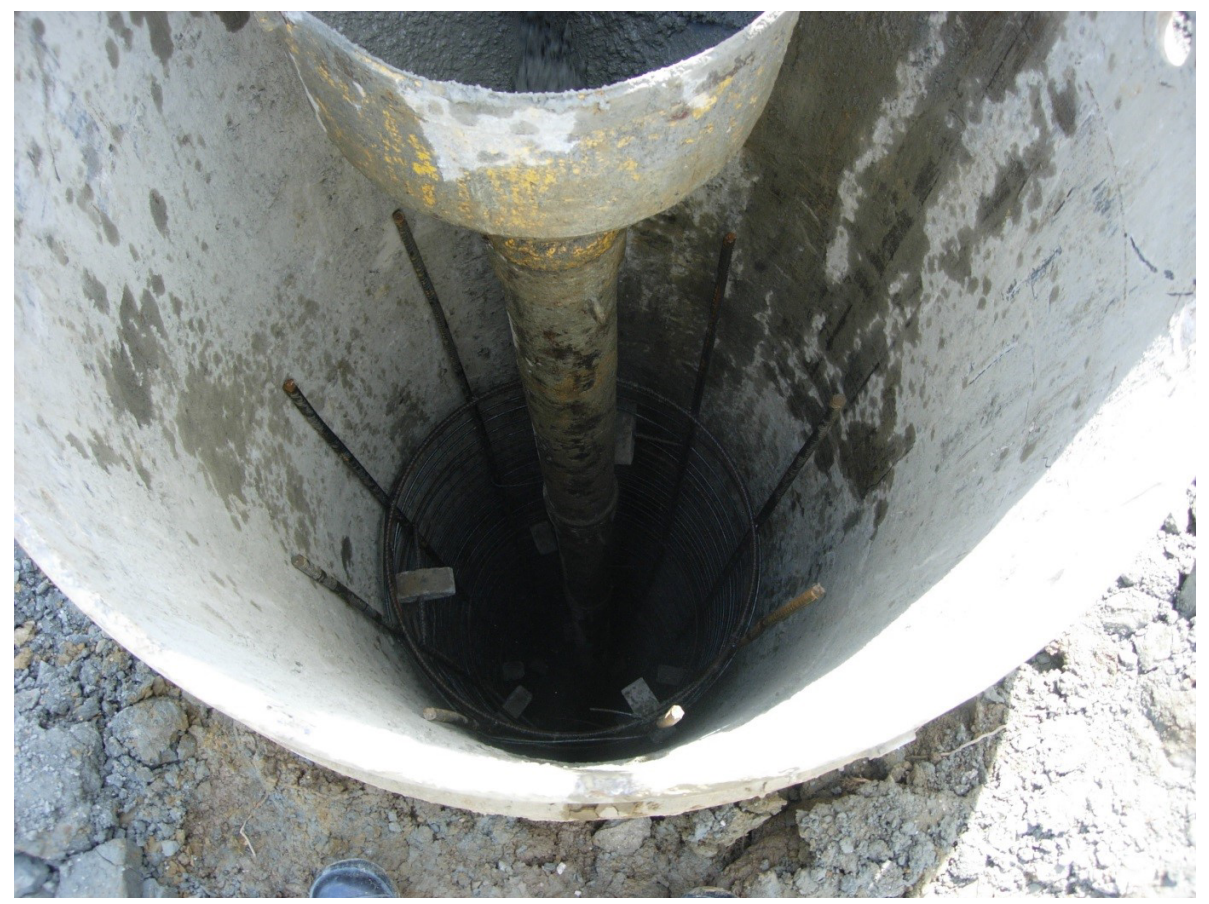

Fig. 2. Placement of the distance wheels.

\subsection{Concreting}

Concreting is being performed with a hopper and its extensions to the desired length to ensure the concrete will not undergo defragmentation due to a falling a large distance. Great time costs can happen to a constructer when following this procedure. Several of temporally removal of the hopper and adjusting the extension to desired length and then returning the hopper back during concreting is very time consuming. Constructors often use only the upper part of the hopper which makes the concreting much faster. However, the result is poor quality and nonhomogeneous concrete.

A very delicate matter is concreting the head of the pile. Water is often leaking through the casing during the concreting. Dirt is falling into the drilled hole and everything is being pushed upwards by the concrete paste. Therefore, it is necessary to concrete head of the pile with extension connected to the concrete paste a thus pushing the water and dirt to the surface. Concreting should be done only to the specified height which exceeds the head of the pile and after hardening of the concrete paste removal of the poor quality concrete is necessary.

While following this procedure several problems can occur during finishing of the concreting. Concrete paste might not be able to push the dirt through inserted extension upwards. Pulling out the extension happens to be often the solution however dirt and water will be released into the area of the head of a pile. Thus poor quality concrete will be located at the most stressing part of the pile. Afterwards shutter is being put on and the rest of the concreting is being done without extension with high quality concrete thus making an impression of high quality concrete within the head of the pile although there is poor quality concrete just below it. See Fig. 4 and 5 .

Concreting must solely be done continuously without interruptions. It is necessary to push dirt above the head of the pile and remove any leftover concrete. 


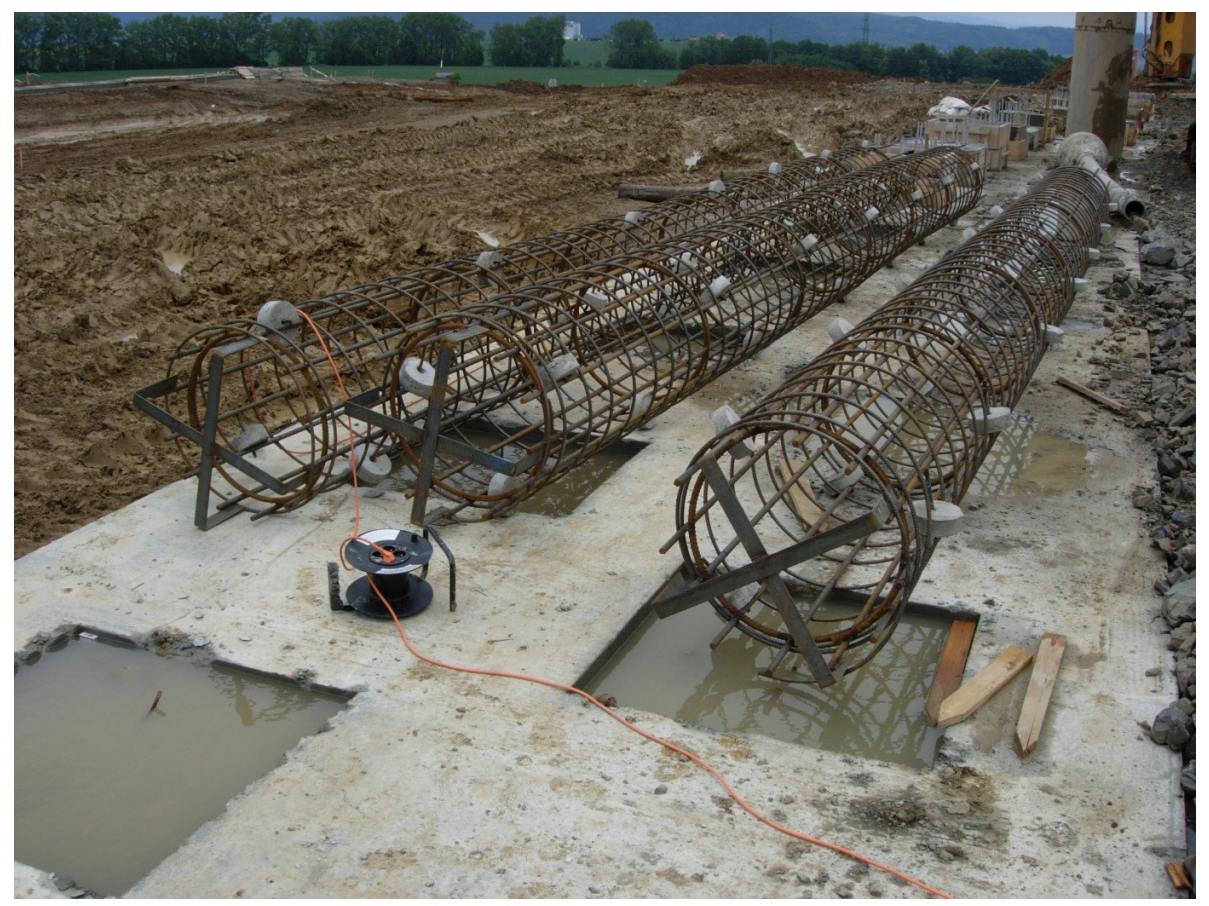

Fig. 3. Pile reinforcement.

\subsection{Concrete sampling}

There is concrete sampling before the concreting according to the relevant standards. During the concreting sampling occurs when in doubt. Common mistake is to take samples from the head of the pile after concreting interruption and using new high quality concrete paste.

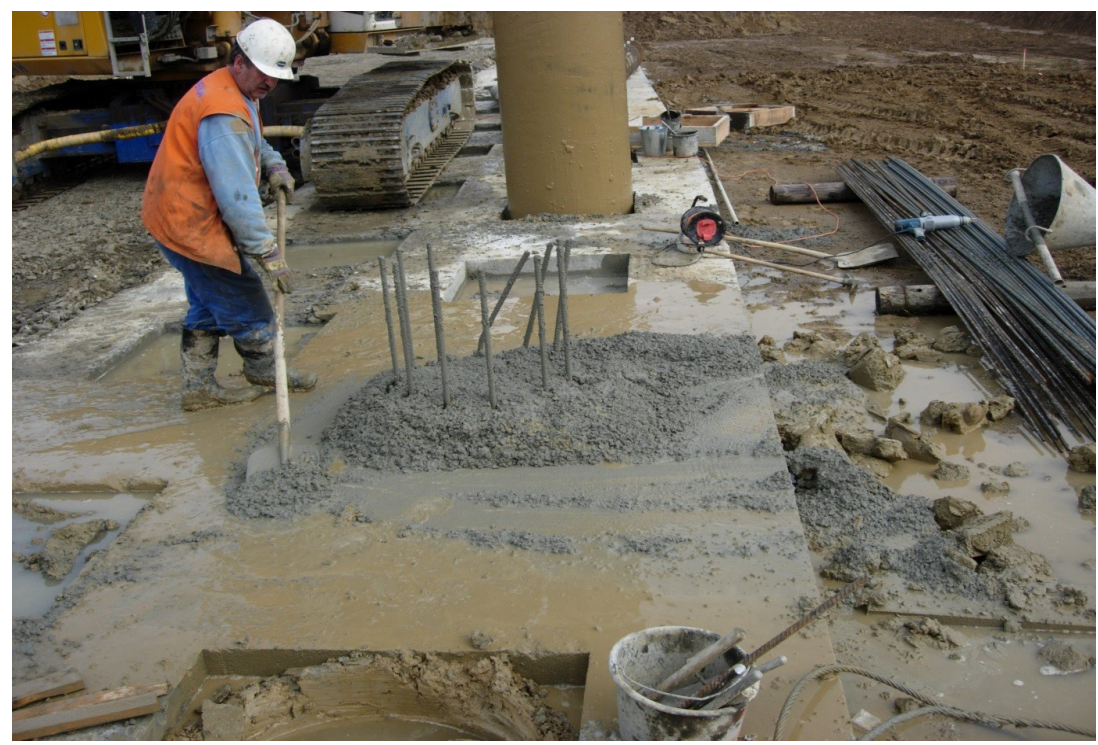

Fig. 4. Pile concreting. 
The significance of sampling is to take sample during nonstandard procedures such as prematurely pulled out extensions, water and dirt detection in the concrete paste.

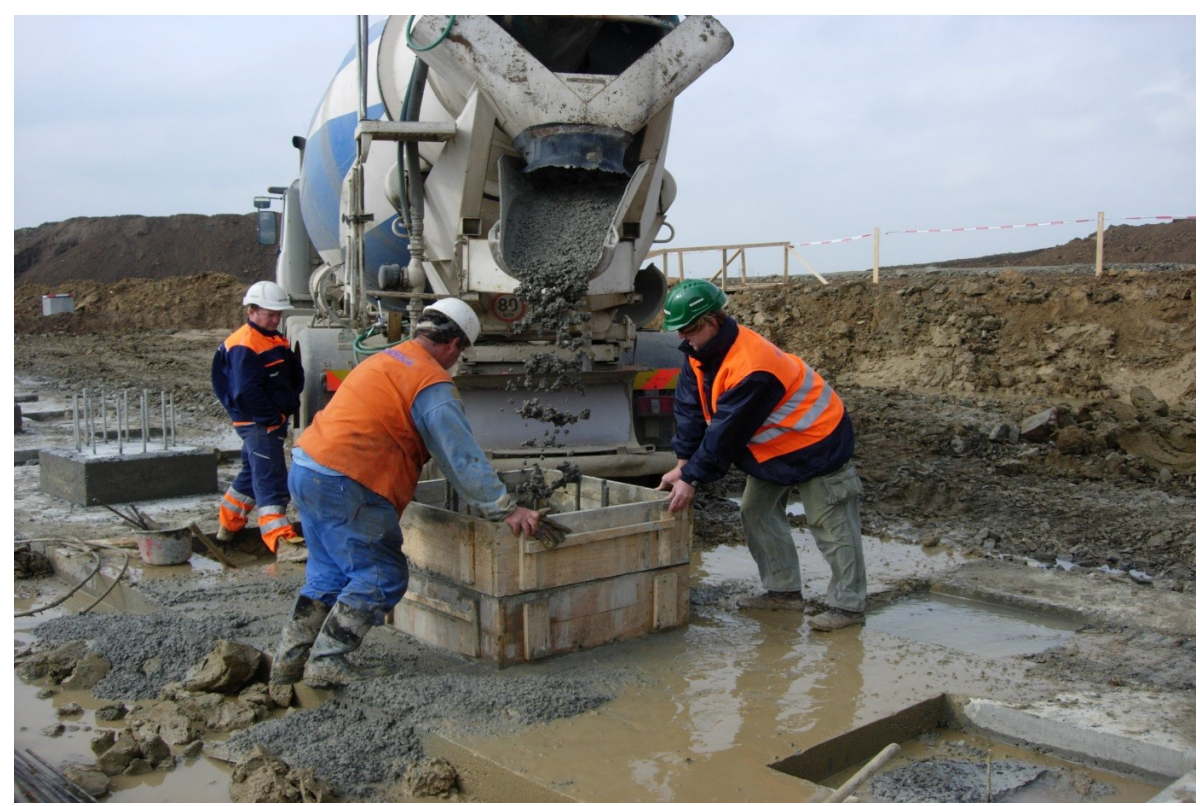

Fig. 5. Heads of pile concreting.

\section{Conclusions}

The purpose of this article was not to describe in details all the problems connected with defects and fails of large diameter drilled piles. It was to point out some of them. Based on his experience the first author recommends following:

- Usage of concrete distance wheels, precisely geometrically manufactured and correctly placed on pile reinforcement.

- To have each layer of distance wheel rotated against each other.

- Thoroughly follow proper concreting procedure especially using sufficiently long extension.

- With regard to manipulation to design sufficient solid pile reinforcement.

- Removal of concrete above a head of the pile.

- Take samples in doubts.

\section{References}

1. F. Irgens, Continuum Mechanics (Springer Verlag, 2008)

2. G.E. Mase, Schaums Outline Series: Theory and Problems of Continuum Mechanics, (McGraw Hill Inc, 1970)

3. J.F. Wendt, Computational Fluid Dynamics, An Introduction (Springer, 1992)

4. H. Mori, Y. Tanigawa, Simulation Methods for Fluidity of Fresh Concrete (Mem. Of the School of Eng. Nagoya Un., 1992)

5. N. Roussel, Steady and transient flow behaviour of fresh cement pastes, Cem. Concr. Res. 35 (2005) 